\title{
Development of methods of production in natural aromatic production
}

\author{
Natalia Frolova, Anatoly Ukrayinets
}

\author{
National University of Food Technologies, Kyiv, Ukraine
}

Keywords:

Aromatic

Essential

Oils

Natural

Chromatography

Article history:

Received

02.07.2018

Received in revised

form 21.09.2018

Accepted

27.12.2018

\section{Corresponding \\ author:}

Natalia Frolova

E-mail:

frolovan809@

gmail.com

DOI:

$10.24263 / 2304-$

974X-2018-7-4-13

\section{Abstract}

Introduction. The analytical and experimental researches on methods of natural aroma sources separation with obtaining individual flavoring substances were conducted. Advantages of fractional distillation and preparative chromatography were demonstrated.

Materials and methods. The essential oils of Moldavian dragonhead and lemon, the model matrix (a blender of terpene hydrocarbons and their oxigen-containing derivants of both known and unknown composition) were studied. The methodologies of gas chromatographic analysis were used. The separate fractions of aimed aromatic components were obtained using preparative chromatography.

Results and discussion. The vacuum separation of essential oils into fractions under the set control regimes of temperature of the still and knob, ${ }^{\circ} \mathrm{C}$, respectively on the levels: the first fraction 67-69, 18-24; the second fraction - 112-118, 25-30; the third fraction $-130-135,32-39$; pressure value, $\mathrm{kPa}$ for fractions: the first $-0,92$, the second $-0,62$, the third $-0,33$; reflux ratio for fractions: the first $-7: 1$, the second $-10: 1$, the third $-5: 1$ allows obtain fractions of different aroma, that significantly widens assortment of natural sources of aroma. Besides, with fractional distillation deterpenization is conducted; using it out of an essential oil the components, that discernibly worsen organoleptic properties, are separated. The deterpenization regime of lemon essential oil temperature of the still and knob, ${ }^{\circ} \mathrm{C}$, respectively $67-70,17-19$; pressure $-2,64 \mathrm{kPa}$, reflux ratio $-1: 3$.

In order to extract essential oils preparative chromatography with development of the special column was used; a solid carrier Chromosomorb A and a stationary phase PEG-6000 were selected. The terms of preparative separation on a column filled with with a stationary phase,

In order to extract essential oils fractions in the individual mode by the method od of preparative chromatography, a special column with a number of plates 600 was developed, which makes it possible to simulate the fractionation process on the razor column of a rectification unit. During the research, a solid carrier,

The effective regimes of the process were established experimentally: the carrier gas flow rate, $\mathrm{sm}^{3} / \mathrm{min}-85-90$; sample value $-0,8-1,0 \mathrm{~cm}^{3}$, temperature value, ${ }^{\circ} \mathrm{C}$ : evaporator $-180-250$, column thermostat $-120-200$, detector $-220-250$, fraction collector - 180-250.

Conclusion. The vacuum fractioning of essential oils allows obtaining separate fractions of different aroma. Further preparative separation of fractions provides obtaining individual flavoring substances of pure composition. 


\section{- Food Technology}

\section{Introduction}

In nature individual substances are found mainly in mixtures. The effectiveness of the separation of complex mixtures is important, both in industrial production and in scientific research of a preparative and analytical nature.

The separation process (operation) allows to receive from an original mixture of components several fractions of components with a new quantitative composition, and often, and other qualitative characteristics. Within certain tasks separation of the mixture leads to a receipt of individual components in their pure form.

\section{Analysis of recent researchs and publications}

By the nature of the process used, the operations of crystallization, freezing, forerunning, evaporation, distillation, rectification, relate to physical methods based on phase transitions over temperature changes. Difference in mass, concentration, abundance, viscosity, size, shape, polarity, charge and what is more way of conduct in fields and environments of different nature are also used.

These are processes of extraction, filtration, gel filtration, sedimentation, centrifugation, flotation, screening, electro dialysis. To this category may be attributed separation in liquids of different polarity, density, magnetic separation and others.

Usually, a difference in aggregate state allows separation mixtures into fractions. Enrichment of a fraction with a target component happens on differences in concentrations and temperatures, electrical charges or electrolytic dissociation constants (electrophoresis) with zone refining, different chemical methods [1].

However, majority of classical methods are ineffective for the production of natural or synthetic substances in pure form necessary for manufacture of numerous health and medical products. Also, research and test of the healing or therapeutic effect of complex mixtures of biologically active substances, in particular hydrocarbons, biopolymers, nucleotides, proteins, peptides, antibiotics, etc. may be conducted only after the mixture is separated into fractions and the target substances are isolated in their pure form and identified by known methods of chemistry of pure substances.

The methods of separation that are commonly used to produce biologically active substances are supercritical $\mathrm{CO}^{2}$-extraction, usage of microwaves, isolation of natural products by ion-exchange methods, preparative chromatography. A combination of different methods is often used [2].

In the analysis published by Mc Clements [3], it is stated that in methods for the processing of aromatic sources described in 234 randomly selected works $78 \%$ primarily use forerunning. In other cases there is extraction. At the same time, in many cases, extraction is only a preliminary stage after which forerunning is used.

A rectification under high and medium vacuum [4], selective adsorption [5], fractional extraction and condensation [6], ultrasonic treatment, microwaves treatment [7], turbohydrolysis distillation [8], steam and water distillation [9] are also common. The effectiveness of the method of separation, its selectivity increases with the use of multi-stage processes, such as chromatography. This is due to the high efficiency of the selection of selective sorbents to separating components of the mixture.

A chromatographic separation of a complex mixture happens as a result of uneven distribution of components of the mixture between the stationary and moving phases, which is due to different affinity of separate components to these phases or different ability to diffuse in these phases. Chromatographic methods are classified according to the principles 
underlying the separation processes. In adsorption chromatography a different adsorption capacity of even very close by structure substances is used. With the creation and physic and chemical study of new selective adsorbents, sensitive to the structural or electronic characteristics of the substances analyzed relevant task [10].

In the group of terpenes and terpenoids which are part of the essential oils there are a lot of unstable position isomers and optical isomers. Gas chromatography is most often used for their separation and research. The separation in liquid chromatography is based on different solubility of components in two mixed liquids. Specific biochemical interactions allow selectively separate substances in affinity chromatography [4].

Mixture separation by method of chromodislation [11] happens at the expense of multiple processes of condensation/evaporation of substances on the surface of an inert sorbent inside the stuffing column (or on the surface of a capillary column without a stationary phase).

To increase the effectiveness of the process, a negative temperature gradient along the column (thermal chromodistilation) or injection before the mixture a substance into the column with volatility higher than the volatility of the lightest component of the mixture (restrictive chromodislation) may be used.

To the methods of obtaining the individual components of a complex mixture can be attributed high speed counter current chromatography. This is a versatile dividing method that does not require usage of a solid fixed phase.

Specific chromatographic methods include the following: ion exclusion, longevity of ions, electronic exchange or oxidation-reduction chromatography, ligand chromatography, solubilization chromatography etc [12].

Nowadays, more and more companies are developing constituents of modern therapies (including products for gene therapy), based on data from macromolecules and their allocation and purification are becoming increasingly important. An e xcretion of such molecules involves usage of chromatographic methods ("biochromatography") [13].

Preparative chromatography is not inferior to the indicated methods and even surpasses them in obtaining individual substances of high purity. In this case, each of the separated substances after leaving the chromatographic system gets into a separate receiver [14].

In nutrition products the concentration of substances of interest to the study may be less than one billionth of a particle, and therefore only extremely small amounts of these substances are available for analysis even after their selection and concentration [15].

A performance of preparative chromatography when separating a mixture of substances that determine the taste and aroma is well known. In such cases when the difference in vapor pressure is small and, as a result, the separation ratios for distillation are small, preparative chromatography has significant advantages over distillation through the use of highly selective sorbents [16].

It is difficult to give preference to any of the abovementioned methods. It is necessary to take into account the nature of the complex mixture, the form of its existence in separate components, the complexity, accessibility and duration of the division, the ability to combine with other stages of the process.

Production of food flavors is one of the most dynamic fields of the world food industry. For today the volume of the flavors market in the EU varies from 6 to 7.8 billion euros, according to various estimates, and this figure will increase every year [17].

Today's food industry widely uses various flavors. The problem is that the existing food flavors production in the country is not able to meet the existing demand for such products. As a result, the average annual import of flavors in the market is estimated at more than $96 \%$. Obviously, this can be explained by the lack of domestic innovation, the high cost of foreign 
technology [18].

That is why the innovative activity in the field of production of domestic natural food aromatics, the development of new technologies, the search for little-known, non-traditional sources of natural flavor for food production, the formation of fundamentally new ideas for their effective processing are relevant.

There are two decisive criteria in choosing the method of processing natural sources of aromatic substances. Firstly, taking into account, that the loss of aromatic substances even in the smallest quantities leads to a change in product flavor. Secondly, it is the complete exclusion of chemical or enzymatic adverse reactions that may alter the component composition.

\section{Materials and methods}

\section{Materials}

The materials of research is commercial essential oils of cumin and lemon. The model matrix (a blender of terpene hydrocarbons and their oxigen-containing derivants of both known and unknown composition) under boiling temperature was divided into separate factions of flavoring components.

\section{Distillation of essential oils}

Essential oils were divided into separate fractions by the target components with distillation , which were identified as the most valuable carriers of the aroma for a given nutritional basis.

\section{Gas chromatographic studies of component composition of fractions and aromatic components}

Each stage of the separation of the essential oils was accompanied by gas chromatographic studies of component composition of fractions and aromatic components with usage of an analytical column with a medium polar immobile phase dinonylphthalate.

The following devices were used for the research: chromatic mass spectrometer "HP 5890 Series II (Hewlett-Packard, USA), infrared spectrophotometer UR-20, Germany, spectrophotometer "Specord UV VIS", Germany, spectrophotometers SF-10, SF -46.

Metrological assessment of gas chromatographic measurements was carried out with the assistance of the hardware and software complex "Chromoprocessor-5"

\section{Preparative separation of essential oils}

Preparative separation of essential oils at boiling temperature was held under such conditions: the injector temperature $-200^{\circ} \mathrm{C}$, the thermostat columns temperature $-70-200$ ${ }^{\circ} \mathrm{C}$, the detector temperature $-200{ }^{\circ} \mathrm{C}$, carrier gas flow rate $-80-100 \mathrm{~cm}^{3} / \mathrm{min}$, sample volume $-0,8-1,0 \mathrm{ml}$, potentiometer chart bar speed -10 or $20 \mathrm{~cm} / \mathrm{min}$, detector-catharometer. The factions were picked into an absorber, the original design of which allowed to achieve the maximum degree of enrichment of key components.

\section{Production preparative column}

To get fractions of essential oils in the individual mode of preparative distillation, were developed the basics of separate column with the number of theoretical plates -400 ; solid 
carrier - chromosorb A (producer "Johns Manville" (USA) and stationary phase - PMS-100 of "Peaxim" production were chosen. The following process conditions are set: the injector temperature $-200{ }^{\circ} \mathrm{C}$, the thermostat columns temperature $-70-200{ }^{\circ} \mathrm{C}$, the detector temperature $-200{ }^{\circ} \mathrm{C}$, carrier gas flow rate $-1,0 \mathrm{~cm}^{3} / \mathrm{min}$, hydrogen $-33 \mathrm{~cm}^{3} / \mathrm{min}$, air -330 $\mathrm{cm}^{3} / \mathrm{min}$, sample volume $-0,5-0,8 \mathrm{mcl}$.

\section{Statistical analysis}

Data were expressed as means \pm standard deviations for triplicate determination. Differences were considered to be significant at validity of $\alpha=0.95$.

\section{Results and discussion}

\section{Vacuum separation of essential oils for getting fractions of different flavors}

In our country, a number of types of spicy-aromatic raw materials is not wide enough. For the expansion of the aromatic palette it is proposed to recycle directly essential oils, complex mixtures of components with their own aroma.

The peculiarity of the classical essential oil production is that fresh essential oil may not be immediately used, because it does not meet the standard quality. It takes time and additional operations on which the oil becomes marketable. This increases the material costs.

A viable alternative to the processing of essential oils of different quality is controlled dispersion into fractions. Since this is a physical process, the resulting fractions are natural flavors. Also, the components of fast flavor modification are removed on purpose.

According to the classical laws of forerunning, when the complex mixture is heated to a boil, the components whose elasticity of steam is higher than the others, will first of all go into the steam phase. Fractional forerunning is essentially the opposite of forerunning.

In fractional forerunning, the processes of evaporation and condensation are repeated many times, and the distillate becomes the starting material for the next process every time. As a result, even low-boiling components condense [9].

As a result of fractional forerunning, a number of separated one from another fractions, boiling in the narrow temperature limits, is formed [19]. Difficulties of fractional forerunning of aromatic substances natural sources are primarily associated with a number of component composition, with a wide range of individual boiling temperatures $\left(\mathrm{T}_{\text {boil }}\right)$, an ability of components to chemical modification [20].

According to the classical theories, to the main controlling modes of fractional forerunning are attributed: an operating temperature and pressure [21], in particular absolute pressure from 1 to $100 \mathrm{~mm} \mathrm{Hg}$ on Torr $(0,13-13,33 \mathrm{kPa})$ and $\mathrm{T}_{\text {boil }}$ from 0 to $120^{\circ} \mathrm{C}$. When determining the operating parameters of temperature and pressure of forerunning there comes a dilemma. Typically, the pressure is chosen such that the temperature of the forerunning ensures an effective condensation of distillate vapors with the most available refrigerants, such as water or air. Taking into account the average temperature of flowing cooling water about $20^{\circ} \mathrm{C}$, the condensation temperature of the components should not exceed $45-50{ }^{\circ} \mathrm{C}$. Also it is necessary to highlight the decomposition, at high forerunning temperatures, of essential oils components with the formation of connections of uncontrolled aroma.

At the same time, there are some difficulties concerning lowering the pressure of the process. First of all, tangible fluctuations of temperature within the limits of $10-15^{\circ} \mathrm{C}$ at the beginning of forerunning, decrease of general speed of mass transfer and, accordingly, increase of distillation duration are felt. At the same time, the hardware design becomes more 
complicated with a need to use a powerful vacuum system [22]. Also, fractional forerunning is expedient to carry out in cases of close to $T_{\text {boil }}$ essential oils components. The difference in $\mathrm{T}_{\text {boil }}$ of these components in a vacuum can be much greater than at atmospheric pressure. According to [23], a significant amount of substances that boil at atmospheric pressure at a temperature of $250{ }^{\circ} \mathrm{C}$ and above with decomposition are dispersed without changing the composition at a pressure of $1.33 \mathrm{kPa}(10 \mathrm{~mm} \mathrm{Hg})$ and a temperature of $160-210{ }^{\circ} \mathrm{C}$, or within the temperature range from 100 to $130^{\circ} \mathrm{C}$ at a pressure of $0.00133 \mathrm{kPa}(0.01 \mathrm{~mm})$, or at temperatures from 40 to $60^{\circ} \mathrm{C}$ in vacuum.

Data on the dependence of the effective parameters of fractional forerunning is limited. The table 1 lists the technological map of cumin essential oil dispersal

Table 1

Technological map of cumin essential oil dispersal

\begin{tabular}{|c|c|c|c|c|c|}
\hline \multirow[t]{2}{*}{ Fraction } & \multicolumn{2}{|c|}{ Temperature, ${ }^{\circ} \mathrm{C}$} & \multirow{2}{*}{$\begin{array}{l}\text { Pressure, } \\
\text { kPa }\end{array}$} & \multirow{2}{*}{$\begin{array}{l}\text { Reflux } \\
\text { ratio }\end{array}$} & \multirow{2}{*}{$\begin{array}{l}\text { Content, } \\
\% \text { mass }\end{array}$} \\
\hline & still & port & & & \\
\hline Warmup of the column & $50-65$ & - & 2,64 & $\infty$ & - \\
\hline The first & $67-69$ & $18-24$ & 0,92 & $7: 1$ & $4,5 \pm 0,1$ \\
\hline The second & $112-118$ & $25-30$ & 0,62 & $10: 1$ & $40,2 \pm 1,2$ \\
\hline The third & $130-135$ & $32-39$ & 0,33 & $5: 1$ & $19,7 \pm 1,2$ \\
\hline Distillation residue & - & - & 0,33 & - & $32,8 \pm 2,0$ \\
\hline & & & & Losses: & $2,8 \pm 0,5$ \\
\hline
\end{tabular}

Fixation of losses at the level of $2.8 \pm 0.5 \%$ is due to incomplete capture of the low boiling components, loss of "clogging" the column.

Studies have shown that the vacuum separation of essential oils allows getting fractions of different flavors, which greatly extends the range of natural sources of aroma. Such technological technique does not destroy natural structural bonds of components of essential oils, preserves their naturalness and biological ability, being characteristic for natural plant raw materials.

\section{Modes of lemon essential oil deterpenization}

Under established regimes, a fractional dispersion is carried out with a deterpenization during which components, which are easily oxidized into uncontrolled compounds and significantly degrade the organoleptic properties are removed from the essential oil (Table 2).

Table 2

Working modes of lemon essential oil deterpenization

\begin{tabular}{|c|c|c|c|c|c|}
\hline \multirow{2}{*}{$\begin{array}{c}\text { Stages of } \\
\text { deterpenization }\end{array}$} & \multicolumn{2}{|c|}{ Temperature, ${ }^{\circ} \mathrm{C}$} & \multirow{2}{*}{$\begin{array}{c}\text { Pressure, } \\
\text { kPa }\end{array}$} & \multirow{2}{*}{$\begin{array}{c}\text { Reflux } \\
\text { ratio }\end{array}$} & \multirow{2}{*}{$\begin{array}{l}\text { Content, } \\
\% \text { mass }\end{array}$} \\
\hline & still & port & & & \\
\hline Column warmup & $50-65$ & $14-15$ & 2,64 & $\infty$ & - \\
\hline Terpene fraction & $67-70$ & $17-19$ & 2,64 & $1: 3$ & $30,0-32,0$ \\
\hline Oxygenated fraction & $84-96$ & $30-36$ & $0,66-0,33$ & $1: 14$ & $60,0-62,0$ \\
\hline Distillation residue & $115-127$ & - & 0,33 & - & $4,55 \pm 0,5$ \\
\hline & & & & Losses & $2,0-6,0$ \\
\hline
\end{tabular}


A confirmation of the effectiveness of the essential oils separation method was made by the sensory evaluation of the obtained fractions as independent natural flavors:

- Flavor «Resinous coolness». Flavor composition: fraction 1 cumin dragonhead essential oil. Appearance: liquid. Aroma: coniferous, with a note of mint.

- Flavor «Citrus». Flavor composition: fraction 2 cumin essential oil. Appearance: liquid. Aroma: harmonious, resembles the smell of citrus.

- Flavor «Faded rose». Flavor composition: fraction 3 cumin essential oil. Appearance: liquid. Aroma: tender, of dried rose leaves.

\section{Use of preparative chromatography for the allocation of individual aromatic substances}

Obviously, in various industries, including food industry, there is a shortage of individual aromatic substances of "pure composition". "Purity" is usually considered by a degree of minimization of the amount of admixture. For usage of synthetic intermediates purity is $85-95 \%$ is believed to be enough. A level of admixtures in natural products can be considered sufficient when the concentrations reach $50-75 \%$. The standard substances for analysis require a purity of $99 \%$ and more [24].

The use of preparative chromatography (PG) for the allocation of individual aromatic substances is motivated by the fact that the preparative selection, due to the versatility of selective fixed phase selection, significantly exceeds periodic rectification, and the specific productivity of the preparative collection of pure substances $\mathrm{P}_{\mathrm{m}}$ is fixed within $2 \ldots 6 \mathrm{~g}$ /year, which correlates with the performance of rectification. Herewith, obtaining "pure" individual substances $(\eta=90 \ldots 98 \%)$ is provided with significantly lower operating expenses. In order to extract essential oils fractions in the individual mode by the method od of preparative chromatography, a special column with a number of plates 600 was developed, which makes it possible to simulate the fractionation process on the razor column of a rectification unit. During the research, a solid carrier, a stationary phase, and special devices of a preparative chromatograph have been selected [25].

An effective conductor for preparative column was developed with gradient application of motionless phase PEG6000 on separate sections of solid support (SS, Hromosorb A). So, the first portion of PEG6000in amount of $25 \%$ has to be applied on the first solid support section, the second portion in amount of $20 \%$ on the second solid support section. The third solid support section is recommended to be divided into two parts. On the first solid support part PEG6000 was applied in amount of $17 \%$ and on the second part in amount of $15 \%$. Such a sequence of application of the motionless phase on the solid support provides high selectivity of PG column and reduction of separation duration [26]. The terms of preparative separation on a column, established experimentally and are listed in Table 3

Table 3

Terms of preparative excretion and concentration of individual aromatic substances of essential oils

\begin{tabular}{|c|c|c|}
\hline \multicolumn{2}{|c|}{ Indicator } & Indicator values \\
\hline \multicolumn{2}{|c|}{ Carrier gas flow rate, $\mathrm{sm}^{3} / \mathrm{min}$} & $85-90$ \\
\hline \multicolumn{2}{|c|}{ Sample value } & $0,8-1,0 \mathrm{ml}$ \\
\hline \multirow{5}{*}{ 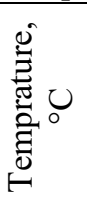 } & Evaporator & $180-250$ \\
\hline & Column thermostat & $120-200$ \\
\hline & Fraction collector & $180-250$ \\
\hline & Dewar flask & $(-20)-(-15)$ \\
\hline & Detector & $220-250$ \\
\hline
\end{tabular}


In researches a special trapper of individual substances, the construction of which allowed reaching the maximum degree of enrichment of the received fractions was used.

In Table 4 the value of the degree of coincidence of mass-spectras of individual substances excretioned from essential oils and their library analogues are listed.

Table 4

Degree of coincidence (\% purity) mass-spectras of individual substances with the library analogues

\begin{tabular}{|l|l|l|l|}
\hline \multicolumn{1}{|c|}{$\begin{array}{c}\text { Individual } \\
\text { substances }\end{array}$} & \multicolumn{1}{|c|}{$\begin{array}{c}\text { \% composition } \\
\text { purity }\end{array}$} & \multicolumn{1}{|c|}{$\begin{array}{c}\text { Individual } \\
\text { substances }\end{array}$} & $\begin{array}{c}\text { \% composition } \\
\text { purity }\end{array}$ \\
\hline 1- linalool & $96,0 \pm 0,2$ & Linalyl acetate & $94,0 \pm 0,2$ \\
\hline$\alpha-$ pinene & $98,0 \pm 0,1$ & $\beta$-phellandrene & $94,0 \pm 0,2$ \\
\hline$\beta-$ myrcene & $98,0 \pm 0,1$ & $\alpha$-phellandrene & $98,0 \pm 0,1$ \\
\hline $\mathrm{n}$ - cymene & $96,0 \pm 0,2$ & $\alpha$ - terpineol & 99,0 \\
\hline d- limonene & 99,0 & d- carvone & 99,0 \\
\hline Convergence of values is not less $0,95 \%$. & \\
\hline
\end{tabular}

The conducted identification confirmed receipt of the expected individual substances from essential oils to $98 \pm 0.15 \%$ of the composition purity. listed.

In Table 5 the results of sensory analysis of essential oils individual substances are

Table 5

Individual substances organoleptic indexes

\begin{tabular}{|l|l|l|}
\hline Individual substances & Taste & Aroma \\
\hline$\beta$-myrcene & Bitterish & Resinous- citrus \\
\hline Cineol & Refreshing & Citrus \\
\hline $1-$ linalool & Bitterish & Lavender with a wood tone \\
\hline $\mathrm{n}$ - cymene & Pungent & Peppermint note \\
\hline $1-, \alpha-$ phellandrene & Pungent & Terpene \\
\hline $1-, \beta$-phellandrene & Moderately bitterish & Mint with a citrus note \\
\hline $\mathrm{d}-$ limonene & Moderately bitterish & Earthy lemon \\
\cline { 3 - 3 } $\mathrm{d}-$ linalyl acetate & & Bergamot note \\
\hline $\mathrm{d}-, \alpha-$ terpineol & Herbaceous & Reminds lilac \\
\hline $1-\alpha-$ pinene & Spicy & Needle \\
\hline $\mathrm{d}-$ carvone & Pungent & Dill note \\
\hline $1-$ cariofilen & Pungent & Wood \\
\hline & & \\
\hline
\end{tabular}

Received individual substances of pure composition have value as test-standards in diverse researches, including pharmacokinetic and metabolic researches of impact of natural sources of aroma on human body's organs and systems.

Individual substances organoleptic indexes are the information base for technologists in the development of formulations of flavored products of various industries, while creating compositions of aromas of stable characteristics. 


\section{Conclusion}

In the development of methods of separation in the production of natural flavors, it is proposed and scientifically substantiated the treatment of essential oils by dispersal to narrow fractions of different flavors and further preparative allocation of individual substances of pure composition. The efficiency of new solutions in the manufacture of a stationary phase preparative column PEG6000 is shown in portions on the section of the solid carrier chromosorb A. The column with the number of theoretical plates 600 allows to simulate the fractionation process on the hopper column of the distillation unit.

Received individual substances of pure composition have value as test-standards in diverse researches, including pharmacokinetic and metabolic researches of impact of natural sources of aroma on human body's organs and systems.

\section{References}

1. Sarker S. D., Latif Z., \& Gray A. I. (Eds.), (2006), Natural products isolation (Vol. 20), Springer Science \& Business Media.

2. Rybkin V.V. (2010), Analytical chemistry and physico-chemical methods of analysis, IGHTU, Ivanovo.

3. McClements D. J. (2015), Food emulsions: principles, practices, and techniques, CRC Press.

4. Diosady L.X.L. (2003), Fats and Oils from Plant Materials, In: Extraction Optimization in Food Engineering, CRC Press.

5. Arce A., Marchiaro A., Rodríguez O., Soto A. (2006), Essential oil terpenless by extraction using organic solvents or ionic liquids, AIChE journal, 52(6), pp. 2089-2097.

6. Komthong P., Katoh T., Igura N., Shimoda M., Hayakawa I. (2006), Ascending bubble extraction of terpenes from freshly squeezed orange juice, Food research international, 39(1), pp. 53-58.

7. Sahraoui N., Vian M. A., El Maataoui M., Boutekedjiret C., Chemat F. (2011), Valorization of citrus by-products using Microwave Steam Distillation (MSD), Innovative food science \& emerging technologies, 12(2), pp. 163-170.

8. Herguijuela J., Pietzonka W., Wildermann A., Wolf T. (2014), U.S. Patent No. 8, 747,621, Patent and Trademark Office, Washington.

9. Stichlmair J.G. (2010), Distillation or Rectification, Chemical Engineering and Chemical Process Technology-Volume II: Unit Operations-Fluids and Solids, 68.

10. Dolgonosov A.M. (2015), Polarity and hydrophilicity - principal independent characteristics of chromatographic stationary phases, Sorption and chromatographic processes, 15(3), pp. 316-320

11. Adams R. P., Sparkman O. D. (2007), Review of Identification of Essential Oil Components by Gas Chromatography/Mass Spectrometry, $J$ Am Soc Mass Spectrom, 18, pp. 803-806.

12. Chamberlain J. (2018), The Analysis of Drugs in Biological Fluids 2nd Edition, CRC press.

13. Zhou J., Sun C., Meng L., Ye W., Luo P., Sun F., Xu X. (2017), A new PPAR $\gamma / D N A$ origami biochromatography and offline high performance liquid chromatography-mass spectrometry method for screening PPAR $\gamma$ receptor antagonists from ginsenosides, Archives of biochemistry and biophysics, 629, pp. 63-69. 
14. Fare D.L., Adamovics J.A. (2017), High-Performance Liquid Chromatography, In: Chromatographic Analysis of Pharmaceuticals, Second Edition, Routledge, pp. 135-208.

15. Aklakur M., Asharf Rather M., Kumar N. (2016), Nanodelivery: an emerging avenue for nutraceuticals and drug delivery, Critical reviews in food science and nutrition, 56(14), pp. 2352-2361.

16. Chopel N.V., Usenko V.O., Frolova N.E., Silka I.M., Naumenko K.A. (2013), Method for separating essential oils and their narrow fractions into pure aromatic components by preparative gas chromatography, Patent for invention No. 102171.

17. Silva V. L., Sereno A. M., do Amaral Sobral P. J. (2018), Food industry and processing technology: on time to harmonize technology and social drivers, Food Engineering Reviews, pp. 1-13.

18. Ukrainian market of perfume and cosmetic products, Available at: http://apcu.ua/rinkovidoslidzhennya-ta-statistichni-dani/parfumernokosmetichnijrinok-ukraini.htm

19. Meirelles A.J., Batista E.A., Scanavini H.F., Batista F.R., Ceriani R., Lima Jr L.F.L. (2008), Distillation applied to the processing of spirits and aromas, Extracting bioactive compounds: Theory and applications, pp. 75-136.

20. Frolova N. E., Frolova N. E. (2017), Theoretical substantiation and development of technologies of natural concentrated flavors from ethereal raw materials.

21. Feoktistov, D.V. (2013), Experimental investigations of the efficiency of the process of distillation of binary substances, Industrial power engineering, 10, pp. 35-39.

22. Wiles S. (1989), Phase equilibrium in chemical technology.

23. Gryta M., Waszak M. (2016), Application of vacuum membrane distillation for concentration of organic solutions, Chemical Papers, 70(6), 737-746.

24. Bogatyuk N.P., Danilova I.L., Pekhova O.A., Timasheva L.A. (2014), A new method of preparing vegetable raw materials for the production of essential oils, Universum, 9(9).

25. Frolova N.E., Usatyuk O.M. (2014), New possibilities for the processing of essential oils for the flavoring of food products, East European Journal of Advanced Technology, 2(12), pp. 24-29.

26. Frolova N.E., Ukrayinets A.I., Sylka I.M. (2016), Using preparative chromatography for excretion of monofactions out of complex mixtures of natural origin, Technological audit and production reserves, 2(4), pp. 21-26. 